\title{
Effect of Surya Namaskara on Mental Health, Self-control and Mindfulness of Adolescent School Children.
}

Niranjan Parajuli ( $\square$ ranjan.happy1@gmail.com)

All India Institution of Medical Sciences, New Delhi

Mutturaj Shindhe

Swami Vivekananda Yoga Anusandhana Samsthana

Balaram Pradhan

Swami Vivekananda Yoga Anusandhana Samsthana

\section{Research Article}

Keywords: Surya Namsakara, Adolescent School children, Self-control, Mindfulness, Mental Health

Posted Date: October 11th, 2021

DOI: https://doi.org/10.21203/rs.3.rs-955629/v1

License: () (i) This work is licensed under a Creative Commons Attribution 4.0 International License. Read Full License

Version of Record: A version of this preprint was published at Complementary Therapies in Clinical Practice on November 9th, 2022. See the published version at https://doi.org/10.1016/j.ctcp.2022.101691. 


\section{Abstract}

\section{Background}

A big portion of adolescent school children suffers from mental health problems. Low self-control and mindfulness are positively associated with poor mental health. Therefore, the present study was designed to assess the effect of Surya Namaskara (SN) on mental health, self-control, and mindfulness among school children.

\section{Method}

63(39 female and 24 male) students (mean age $=14.24$ years and SD $=0.42$ years) studying at $9^{\text {th }}$ grade in a private school in Karnataka, India were recruited as participants of the study. The design of the present study was a non-randomized two arms design. Students in grade 9 section ' $A$ ' ( $N=33$ ) were selected as the intervention group. Whereas, students in grade 9 section ' $B$ ' $(N=30)$ were considered as a control group. Students in the intervention group were given SN for 15 days. The participants were administrated the Brief Self-control Scale (BSCS), Mindfulness, Attention and Awareness Scale for Adolescents (MAAS-A), and General Health Questionnaire-12 (GHQ-12) questionnaires on the baseline and after 15 days of intervention.

\section{Results}

Findings of the present study showed a significant difference in MAAS-A scores $\left[F(1,54)=18.47, p<0.001, \eta_{p}^{2}=0.26\right]$ in within group comparison. There was also a significant interaction (Times*Groups) for BSCS $\left[F(1,54)=4.89, p=0.031, \eta_{p}{ }^{2}=0.08\right]$ and MAAS-A $\left[F(1,54)=6.63, p=0.013, \eta_{p}{ }^{2}=0.12\right]$ scores. Post-hoc analysis showed SN group has significantly high post BSCS score $(p=0.005)$ and MAAS-A score $(p=0.005)$ compared to control group. Similarly, there was a significant high BSCS score $(p=0.003)$ and MAAS-A score $(p<0.001)$ after SN intervention compare to their respective pre scores. There was no significant change in the GHQ-12 scores in both groups in pre-post comparison.

\section{Conclusion}

The finding of the present study showed that SN improves self-control and mindfulness in adolescent school children. However, the results of the current study should be confirmed by future studies with robust research design, a large sample size, and advanced tools.

\section{Background}

Mental health problems are one of the leading causes of disabilities among children and adolescents. 10 to $20 \%$ of adolescents and children worldwide suffer from mental health disorders ${ }^{1,2}$. A systematic review and meta-analysis by Malhotra \& Patra ${ }^{3}$ reported $23.33 \%$ of children and adolescents in India are having psychological illnesses. Mental health problems in adolescents lead to poor academic performance, the repetition of the grade, and droop out from the school ${ }^{4}$. Adolescents with mental health problems also have poor self-rated health, substance misused, early sexual activity, family/peer problems, and developmental-behavioral problems ${ }^{1,2}$. In its worse, mental health disorders can be resulted in suicide. Suicide is the fourth major cause of death in 15 to 19 years old ${ }^{5}$. Mental health disorders like depression, anxiety, psychosocial distress, loneliness, and anxiety-related insomnia are common among children and adolescents $^{4,6-8}$.

Academic pressure, parental expectation, life stress, low socioeconomic conditions are some of the major causes of mental health problems in children and adolescents $^{9-11}$. Apart from these causes, psychological factors like low self-control and low mindfulness also adversely affect the mental health of children and adolescents.

Self-control is the ability to inhibit impulses and delay gratification ${ }^{12,13}$. It is also defined as a cognitive process that allows individuals to self-regulate their behavior in order to achieve personal goals ${ }^{14}$. Individuals with high self-control are emotionally balanced, have better physical and mental health as well as interpersonal relationship ${ }^{15,16}$. On the other hand, low self-control is positively associated with poor mental health, substance abuse, criminal behavior, poor interpersonal relationship, and poor academic performance ${ }^{17}$. It also adversely affects emotional well-being and social relationship ${ }^{18-19}$.

Likewise, mindfulness is defined as the awareness that is developed from paying attention to whatever arises in the present moment with an open and discriminating mind ${ }^{20}$. Mindfulness is an act of developing moment-to-moment awareness and relating all the life experiences (positive, negative, and neutral) in the open and receptive way ${ }^{21}$. Mindfulness is positively correlated with psychological health and subjective well-being ${ }^{22,23}$. A meta-analysis showed individuals with high mindfulness tend to have positive health-related behavior (healthy eating, sleep, and physical activity) ${ }^{24}$. On the contrary, mindfulness is negatively associated with substance use, depression, and post-traumatic stress disorder ${ }^{25}$. Even studies showed low mindfulness in adolescents is positively correlated with stress, anxiety, depression, low executive function, and poor academic performance ${ }^{26-28}$. Thus, there is a requirement of intervention to improve the mental health, self-control, and mindfulness of adolescents.

Yoga can be an effective intervention to enhance adolescent mental health, self-control, and mindfulness. Yoga is a mindfulness-based practice, originated in the Indian sub-continent five thousand years back. The practice of yoga involves sustained attention to physical sensations, breathing and mental activity, restful postures, breathing exercises, and periods of meditative awareness ${ }^{29}$. It contains a contemplative element which is conceptualized as "mindfulness in motion"30. The right practice of yoga with conceptual understanding enhances the overall health and well-being of individuals as well as brings mental peace and calmness. A scientific study showed yoga significantly reduces stress and anxiety ${ }^{31}$. It also decreases depression and improves the quality of life ${ }^{32}$. Yoga 
practice was found to be effective in improving self-control ${ }^{33}$. It even improved the self-control of youth at risk and incarcerated ${ }^{34}$. Studies also reported practice of yoga increases mindfulness ${ }^{35-37}$.

In addition, Rashedi et al. ${ }^{38}$ reported yoga to be an effective practice to enhance positive behavior in children. Yoga helps children and young people to cope with stress and enhances their physical and psychological wellbeing ${ }^{39-42}$. It reduces anxiety, depression, and global psychological stress of school students ${ }^{43}$. Even teachers reported that yoga significantly reduces depression symptoms, behavioral symptoms, and internalizing symptoms of children with emotional and behavioral disorders ${ }^{44}$.

Yoga practice comprises several practices including Surya Namaskara (sun salutation), asana (postures), pranayama (breath regulation), and dhyana (meditation). Surya Namaskara (SN) is one of the basic components of yoga practice. It contains a series of 12 postures. These postures are performed in a cyclical flow. SN's postures are even practiced with breath coordination and chanting mantra. Scientific studies reported the efficacy of SN on improving cardiorespiratory fitness, handgrip strength, flexibility, and endurance as well as helping in weight management among adults and children ${ }^{45-48}$. It also enhances the R disposition of physical relaxation, mental quietness, awareness and joy, and reduces sleepiness and stress disposition of somatic stress, worry, and negative emotion ${ }^{49}$. It is effective in reducing stress and state anxiety ${ }^{50}$. An intensive literature review showed no study to assess the effect of SN on the mental health, self-control, and mindfulness of school children. Therefore, the present study was planned to evaluate the effect of SN on the mental health, self-control, and mindfulness of adolescent students.

\section{Methods}

63(39 females and 24 males) students (mean age $=14.24$ years and SD $=0.42$ years) studying at $9^{\text {th }}$ grade in a private school in Puttur, Karnataka, India were recruited as participants of the study. The design of the present study was a non-randomized two arms design. Students at grade 9 section ' $A$ ' ( $n=33 ; 21$ females and 12 males) were selected as the intervention group. Whereas, students studying at grade 9 section 'B' ( $n=30 ; 18$ females and 12 males) were considered as a control group. The participants were administrated BRIF Self-control Scale (BSCS), Mindfulness, Attention and Awareness Scale for Adolescent (MAAS-A), and General Health Questionnaire-12 (GHQ-12) questionnaires on the baseline and after 15 days of intervention. The numbers of students included in the final analysis from both groups are given in trial profile (Figure 1).

\section{Assessment Tools}

\section{General Health Questionnaire (GHQ-12)}

The GHQ-12 $2^{51}$; a subset of the GHQ-28 is a screening questionnaire for detecting depression, anxiety, and social dysfunction. It is a valid tool to identify probable mood and anxiety disorders in adolescent school children ${ }^{52,53}$. It contains 12 items and each item is rated from one (often) to four (Never). The likert method of scoring was used in this study. Firstly, the answer codes for questions 1, 2, 3, 4, 5, 8, and 9 were re-coded in reverse terms (i.e. 1 to 4 ; 2 to 3 ; 3 to 2 ; and 4 to 1 ) and individual total scores in the GHQ -12 was obtained by summing up all the individual item scores and deducting the sum by 11 . The higher score indicates the worse condition.

\section{Brief Self-Control Scale (BSCS)}

The BSCS is a 13-item self-report questionnaire to assess the individuals' self-control ${ }^{17}$. Participants rate how well each item (e.g., "I blurt out whatever is on my mind") describes them on a 5 -point scale ranging from $1=$ Not at all like me to $5=$ Very much like me. The BSCS is highly reliable and valid tool with high internal consistency (Cronbach alpha $=0.83-0.85$ ) and test-retest reliability (Cronbach alpha $=0.87$ ) to measure the self-control school students ${ }^{17}$. The total score of BSCS was obtained by reversing the score for $2,3,4,5,7,9,10$, and 12 items and summing up all individual item score.

\section{Mindful, Attention and Awareness Scale for Adolescent (MAAS-A)}

The MAAS-A is an adjusted version of the Mindfulness, Attention, and Awareness Scale (MAAS) developed by Brown \& Ryan ${ }^{54}$. One Item ("I drive places on 'automatic pilot' and then wonder why I went there.") was removed from MAAS since it was inappropriate to adolescents ${ }^{55}$. It is a valid tool to assess the mindfulness of adolescents aged 14 to 18 years ${ }^{55}$. This instrument consists of 14 items, which assess the quality of attention and awareness that individuals apply to their daily lives. These items are rated on a 6-point Likert scale ranging from 1 (almost always) to 6 (almost never). Participants' responses to each item are summed to create a total score. The total score can range from 14 to 84 . A high score indicates a high degree of mindfulness.

\section{Intervention}

\section{Surya Namaskara}

Participants in the experimental group were given an hour of SN training for six days a week for two weeks. The session was started with chanting OM for three rounds. Then, warm-up exercise (jogging, side bending, twisting, and forward \& backward bending) was given for five minutes, which was followed by 
practice of twelve poses SN along with breathing. At the end of the session, five minutes of silent relaxation in a supine position was given. The instruction for 12 steps SN was given as follows: Join your hands in front of chest; adopt Namaskara mudra (Salutation Pose). (1) Inhale deeply and raise your arms. Slowly bend backward, stretching arms and keep your elbows straight (Hasthauttanasana - Raised Arms Posed). (2) Exhale slowly bent forward, keep your palms by the side of your feet, and try to bring your forehead to your knees or shins (Padahastasana - Hand to Feet Posture). (3) Inhale and move the right leg away from the body in one big step backward and keep the right knee on the mat. Keep hands and feet firmly on the ground, with the left foot between the hands. Raise your head (Ashwasancalana - Equestrian Pose). (4) With exhalation take the left leg back and keep it together with the right leg. Keep arms straight; slightly lower your hips so that your body will be in a straight line, look forward (Chaturanga Dandasana- Four-Limbed-Staff Pose). (5) With inhalation bend your knees and keep on the mat then rest your hip on the heels, forehead on the mat, and stretch your arms forward (Shashankasana; Rabbit posture). (6) With inhalation move your body forward, keep your knees firm on the mat. Exhale and put your chest on the mat in between your palms. Slightly raise your hips, keep your forearms straight and closer to the chest (Astanga Namaskarasana - Eight Limbed Salutation Pose). (7) Inhale and raise your trunk and bend backward as much as possible, bending the spine to the maximum (Bhujangasana, Cobra Pose). (8) Exhale and raise hips, keep your heels on the mat, elbows straight, push body backward (Parvatasana, Mountain Pose). (9) With inhalation bend your knee and keep on the mat then rest your hips on the heels, forehead on the mat and stretch your arms forward (Shashankasana, Rabbit Pose). (10) Inhale and move the right leg forward in one big step and keep your right foot in between the palms. Keep hands and feet firmly on the ground and left knee on the mat (Ashwasancalana - Equestrian Pose). (11) Exhale slowly and bring your left leg forward together with your right leg, bent forward, keep your palms by the side of your feet, and try to bring your forehead to your knees or shins (Padahasthasana Hand to feet Pose). (12) Inhale and raise the arms. Slowly bend backward, stretch your arms, and keep your elbows straight (Hasthauttanasana - Raised Arm Posed). Exhale and bring the hands down and join your palms in front of your chest; adopt Namaskara Mudra (Pranamasana, Salutation Pose).

Whereas the control group was not given any intervention and was involved in activities they were doing on regular basis.

\section{Data Analysis}

Statistical analysis was done by using IBM Statistical Package for Social Sciences (SPSS) software (version 22). The obtained data were compared using a repeated-measures analysis of variance (RM-ANOVA) followed by Bonferroni adjusted posthoc analyses. The RM-ANOVA had two within-subjects factor 1: times, pre and post, and factor 2: groups, SN and control. All statistical analysis was computed with two-tailed. Parametric tests (i.e., repeated-measures ANOVA followed by multiple posthoc tests) were used since the distribution of data does not impact the accuracy of results when the sample size is greater than $30^{56}$.

\section{Results}

Final analysis included 56 [SN ( $n=30 ; 21$ females and 9 males $)$ and control $(n=26 ; 17$ females and 9 males)] participants. Three participants from the intervention group and four from the control group were excluded from the final analysis for post data being not available. Excluded participants were absent on the day of post-data collection. The group means \pm SD, Cohen's d, and p-value for different variables are given in table 1. ANOVA value for within-subjects factor (times), between-subjects factor (groups), and interaction between two (Groups*times) for different variables are given in table 2.

Table 1

The mean \pm Standard Deviation scores of the Brief Self-control Scale (BSCS), the Mindfulness, Attention and Awareness Scale for Adolescent (MAAS-A) and the General Health Questionnaire-12 (GHQ-12), P values and Cohen's d.

\begin{tabular}{|lllllll|}
\hline Variables & \multicolumn{2}{l}{ Within Group Analysis } & & \multicolumn{2}{l|}{ Between group Analysis } \\
\cline { 2 - 7 } & \multicolumn{2}{l}{ Surya Namaskara } & Control & & \\
& & & & & \\
& PRE & POST & PRE & POST & P Value & Cohen's d \\
\cline { 2 - 7 } & & & & & \\
\hline BSCS & $40.50 \pm 6.13$ & $44.90 \pm 6.41^{* *}$ & $40.53 \pm 5.69$ & $40.31 \pm 5.24$ & 0.005 & 0.78 \\
\hline MAAS-A & $52.17 \pm 11.97$ & $63.37 \pm 13.18^{* *}$ & $51.46 \pm 11.22$ & $54.27 \pm 9.70$ & 0.005 & 0.78 \\
\hline GHQ-12 & $18.83 \pm 2.04$ & $19.80 \pm 2.95$ & $18.69 \pm 2.29$ & $19.46 \pm 2.70$ & 0.66 & - \\
\hline$\star \star$ p $<.01$ & & & & & & \\
\hline
\end{tabular}

Table 2

ANOVA Table for the Brief Self-control Scale (BSCS), the Mindfulness, Attention and Awareness Scale for Adolescents (MAAS-A) and the General Health Questionnaire-12 (GHQ-12), P values and Cohen's d. 


\begin{tabular}{|c|c|c|c|c|c|c|}
\hline \multirow[t]{3}{*}{ Variables } & \multicolumn{6}{|l|}{ Factors } \\
\hline & \multicolumn{2}{|c|}{ Within Subjects Group } & \multicolumn{2}{|c|}{ Between Subjects Group } & \multicolumn{2}{|c|}{ Groups*Times } \\
\hline & $F(1,54)$ & $\mathbf{P}$ & $F(1,54)$ & $P$ & $F(1,54)$ & $p$ \\
\hline BSCS & 3.96 & 0.052 & 3.66 & 0.061 & 4.89 & 0.032 \\
\hline MAAS-A & 18.47 & $<0.001$ & 3.36 & 0.072 & 6.31 & 0.013 \\
\hline GHQ-12 & 3.77 & 0.057 & 0.22 & 0.64 & 0.05 & 0.83 \\
\hline
\end{tabular}

Findings of the present study showed a significant difference in MAAS-A scores $\left[F(1,54)=18.47, p<0.001, \eta_{p}^{2}=0.26\right]$ in within group comparison. There was also a significant interaction (Times*Groups) for $\operatorname{BSCS}\left[F(1,54)=4.89, p=0.031, \eta_{p}{ }^{2}=0.08\right]$ and MAAS $\left[F(1,54)=6.63, p=0.013, \eta_{p}{ }^{2}=0.12\right] \operatorname{scores}$. No significant difference was observed in any of the variables in between group analyses.

Post-hoc analysis showed SN group has significantly high post BSCS score $[p=0.005,95 \%$ of $\mathrm{Cl}(-7.76--1.42)]$ and MAAS-A score $[p=0.005,95 \%$ of $\mathrm{Cl}$ $(-15.39--2.81)]$ compared to control group. Similarly, there was a significant high BSCS score $[p=0.003,95 \%$ of $\mathrm{Cl}(-7.26--1.52)]$ score and MAAS score $[p<$ $0.001,95 \%$ of $\mathrm{Cl}(-15.65--6.75)]$ after SN intervention compare to their respective pre scores. There was no significant change in the GHQ-12 scores in both groups in pre-post comparison.

\section{Discussion}

The present study was conducted with the aim to assess the effect of 15 days SN on mental health, self-control, and mindfulness of adolescents' school children. The findings of the present study showed that SN significantly improves adolescent school children's self-control and mindfulness in comparison to the control group. However, there was not any significant change in mental health after SN intervention.

The finding of the current study showed significant improvement in self-control after SN in between-groups comparison and pre-post comparison. An intensive literature search showed no prior study to evaluate the effect of SN or yoga practice on adolescents' self-control. As per our knowledge, this is the first study to assess the effect of yogic practice on the self-control of adolescents' school children. This study is not directly comparable with the previous study. However, previously Ramadoss \& Bose ${ }^{34}$ and Danielly \& Silverthorne ${ }^{33}$ showed yoga improves self-control. However, these studies differ from the present study in terms of intervention and population. Ramadoss \& Bose ${ }^{34}$ conducted research on vulnerable youth and intervention was a transformative life skills program that consists of yoga poses, pranayama, and meditation. While the population of Danielly \& Silverthorne's ${ }^{33}$ study was female inmates, and the intervention was yoga. Danielly \& Silverthorne ${ }^{33}$ also reported that improvement in self-control after yoga was statistically insignificant.

The exact mechanism behind the improvement in self-control after SN or yoga intervention has not been yet understood clearly. However, earlier studies have shown that yoga enhances executive functions ${ }^{57,58}$. It also increases the volume of the frontal cortex that is associated with self-control and restriction of impulsivity ${ }^{59,60}$. Studies showed self-control is a high-level function that incorporates control of impulsivity, self-regulation, delay of gratification, executive function, and willpower which are basically control by the frontal cortex ${ }^{61,62}$. Therefore, an increase in the volume of the frontal lobe of the brain can be the possible mechanism behind the improvement of self-control after SN intervention.

Similarly, between groups and within-group analyses showed a significant improvement in MAAS-A score after SN. Previously study done by Gaiswinkler \& Unterrainer, Erkin \& Senuzun Aykar and Brisbon \& Lowery also showed that yoga intervention significantly increases mindfulness ${ }^{35-37}$. However, the population of Gaiswinkler \& Unterrainer ${ }^{35}$ was in the age range of 18 to 68 years and the design of the study was cross-sectional. Similarly, Erkin \& Senuzun Aykar's ${ }^{36}$ study participants were nursing professionals. While Brisbon \& Lowery ${ }^{37}$ research participants were advance and beginner yoga practitioners in the age range of 21 to 65 years.

$\mathrm{SN}$, itself is a part of mindfulness-based practice i.e. Yoga. The practice of yoga involves sustained attention to physical sensations, breathing, and mental activity, and periods of meditative awareness ${ }^{29}$. Yoga practice also increases sustain attention and selective attention ${ }^{39}$. These can be the possible reasons for improving mindfulness after SN.

The result of the current study showed no improvement in the mental health outcomes of school children after SN intervention. This finding is inconsistent with the results of earlier research. A prior study reported yoga significantly reduces adolescents' anxiety, depression, and psychological distress ${ }^{63}$. A review by Hagen \& Nayer ${ }^{64}$ also conformed yoga reduces stress, depression, and anxiety as well as improved the mental well-being of adolescents. However, the intervention of Frank et al. ${ }^{63}$ study was the transformative life skills program that compromises yoga postures, breathing practices, and meditation and the duration of intervention was an entire first semester of the school year. This inconsistency of the present study with prior studies could be because of a short period of intervention. In the future, prospective research can be conducted to observe the exact effect of SN on adolescent mental health and well-being.

Though the findings of the present study showed no improvement in mental health outcomes of adolescents' school children after SN, a significant improvement in adolescents' self-control and mindfulness are remarkable findings. Research has reported self-control is positively associated with academic performance, emotional well-being, and social relationship, whereas negatively correlated with substance abuse and criminal behavior ${ }^{17,18}$. Likewise, mindfulness is negatively associated with depression, anxiety, fatigue, substance abuse, and confusion, while positively correlated with better academic performance, life satisfaction, and self-esteem ${ }^{25,28,65}$. Thus, based on the results of the present study, the practice of SN can be given to teenagers' school 
children to improve their self-control and mindfulness which could ultimately enhance their emotional and mental well-being as well as academic performance. It could also prevent and protect adolescents from involving in substance abuse and criminal behavior. Based on the present study, the mental health professionals can discuss the benefits of yoga in their clinic with the parents and teachers of adolescents having poor self-control, mindfulness, and psychological difficulties, and encourage them to arrange regular yoga sessions for their children.

\section{Limitations of Study and suggestion for future study}

The major limitations of the present study are research design, sample size, duration of the intervention, and assessment tools. The design of the current study was none randomize two arms design. This design is unable to minimize selection bias and the effect of confounding variables. Thus, randomized control trials can be conducted in the future to address the limitation of research design in the present research. The sample size of the present study was small. Thus, it would be difficult to generalize the finding of the present study. Future studies can be conducted with large sample size; even a multi-centric study can be conducted to assess the effect of SN on self-control, mindfulness, and mental health outcomes. The duration of the present study was only 15 days, which may not be enough to assess the exact effect of SN in self-control, mindfulness, and mental health outcomes of adolescent school children. Therefore, perspective research can be conducted in the future to assess the exact effect of SN. The present study was also limited by the tools; only selfreported questionnaires were used to assess the self-control, mindfulness, and mental health of adolescent school children. Future studies can be conducted using advanced tools like functional magnetic resonance imaging (fMRI) and electro encephalon graph (EEG) to assess the effect of SN in adolescent school children.

\section{Conclusions}

The finding of the present study showed that SN improved self-control and mindfulness in adolescent school children. On the basis of the present finding, SN can be taught to adolescent school children to enhance their self-control and mindfulness which can ultimately prevent them from severe mental health problems and enhance their overall well-being. However, the results of the current study should be confirmed by future studies with robust research design, a large sample size, and advanced tools.

\section{Declarations}

\section{Authors' Contributions}

NP conceptualized the study and wrote the manuscript. MS collected the data and gave intervention. BP analyzed data and critically evaluated the manuscript. All authors read and approved the final manuscript.

\section{Conflicts of interest:}

We, the authors declare that there are no conflicts of interest.

\section{Prior publication:}

No

\section{Financial support and sponsorship:}

Nil.

\section{Ethical Consideration:}

This manuscript does not contain clinical studies and patient data. This includes healthy participants. However, all procedures performed in the present study were in accordance with the 1964 Helsinki Declaration and its later amendments.

\section{Informed consent:}

The written consent was obtained from the principal of school and parents gave informed consent after receiving information from school principal.

\section{Data Availability statement:}

The datasets generated during and/or analyzed during the current study are available from the corresponding author on reasonable request.

\section{References}


1. Burnett-Zeigler I, Walton MA, Ilgen M, Barry KL, Chermack ST, Zucker RA, et al. Prevalence and Correlates of Mental Health Problems and Treatment Among Adolescents Seen in Primary Care. J Adolesc Heal. 2012 Jun;50(6):559-64. Available from:

https://linkinghub.elsevier.com/retrieve/pii/S1054139X11003491

2. Kieling C, Baker-Henningham H, Belfer M, Conti G, Ertem I, Omigbodun O, et al. Child and adolescent mental health worldwide: evidence for action. Lancet. 2011 Oct;378(9801):1515-25. Available from: https://linkinghub.elsevier.com/retrieve/pii/S0140673611608271

3. Malhotra S, Patra BN. Prevalence of child and adolescent psychiatric disorders in India: a systematic review and meta-analysis. Child Adolesc Psychiatry Ment Health. 2014 Dec 21;8(1):22. Available from: http://capmh.biomedcentral.com/articles/10.1186/1753-2000-8-22

4. Schulte-Körne G. Mental Health Problems in a School Setting in Children and Adolescents. Dtsch Arztebl Int. 2016 Mar 18;113(11):183-90. Available from: http://www.ncbi.nlm.nih.gov/pubmed/27118666

5. WHO. Adolescent mental health. 2020. Available from: https://www.who.int/news-room/fact-sheets/detail/adolescent-mental-health

6. Nair S, Ganjiwale J, Kharod N, Varma J, Nimbalkar SM. Epidemiological survey of mental health in adolescent school children of Gujarat, India. BMJ Paediatr Open. 2017;1(1):e000139. Available from: http://www.ncbi.nlm.nih.gov/pubmed/29637154

7. Mangal A, Thakur A, Nimavat KA, Dabar D, Yadav SB. Screening for common mental health problems and their determinants among school-going adolescent girls in Gujarat, India. J Fam Med Prim care. 2020 Jan;9(1):264-70. Available from: http://www.ncbi.nlm.nih.gov/pubmed/32110602

8. Ranasinghe S, Ramesh S, Jacobsen KH. Hygiene and mental health among middle school students in India and 11 other countries. J Infect Public Health. 2016 Jul;9(4):429-35. Available from: https://linkinghub.elsevier.com/retrieve/pii/S1876034115002099

9. Mendes AV, Souza Crippa JA de, Souza RM, Loureiro SR. Risk Factors for Mental Health Problems in School-Age Children from a Community Sample. Matern Child Health J. 2013 Dec 5;17(10):1825-34. Available from: http://link.springer.com/10.1007/s10995-012-1202-9

10. Deb S, Strodl E, Sun J. Academic Stress, Parental Pressure, Anxiety, and Mental Health among Indian High School Students. Int J Psychol Behav Sci. 2015;2015(1):26-34. Available from: http://journal.sapub.org/ijpbs

11. Reiss F, Meyrose A-K, Otto C, Lampert T, Klasen F, Ravens-Sieberer U. Socioeconomic status, stressful life situations and mental health problems in children and adolescents: Results of the German BELLA cohort-study. PLoS One. 2019;14(3):e0213700. Available from: http://www.ncbi.nlm.nih.gov/pubmed/30865713

12. Gillebaart M. The 'Operational' Definition of Self-Control. Front Psychol. 2018 Jul 18;9. Available from: https://www.frontiersin.org/article/10.3389/fpsyg.2018.01231/full

13. Steptoe A, Poole L. Control and Stress. In: Stress: Concepts, Cognition, Emotion, and Behavior. Elsevier; 2016. p. 73-80. Available from: https://linkinghub.elsevier.com/retrieve/pii/B978012800951200008X

14. Miller K. What Is Self-Control Theory in Psychology?. Positive Psychology.com. 2021 [cited 2021 Sep 27]. Available from: https://positivepsychology.com/self-control-theory/

15. Wills TA, Sandy JM, Yaeger A. Temperament, and Adolescent Substance Use: An Epigenetic Approach to Risk and Protection. J Pers. 2000 Dec 25;68(6):1127-51. Available from: https://onlinelibrary.wiley.com/doi/10.1111/1467-6494.00129

16. Vohs KD, Baumeister RF. Self-Control. In: Encyclopedia of Applied Psychology. Elsevier; 2004. p. 369-73. Available from: https://linkinghub.elsevier.com/retrieve/pii/B0126574103001653

17. Tangney JP, Baumeister RF, Boone AL. High Self-Control Predicts Good Adjustment, Less Pathology, Better Grades, and Interpersonal Success. J Pers. 2004 Apr;72(2):271-324. Available from: http://doi.wiley.com/10.1111/j.0022-3506.2004.00263.x

18. Rosenbaum M, Ronen T. Emotional Well-Being and Self-Control Skills of Children and Adolescents: The Israeli Perspective. In: Mental Well-Being. Dordrecht: Springer Netherlands; 2013. p. 209-29. Available from: http://link.springer.com/10.1007/978-94-007-5195-8_10

19. Miller-Lewis LR, Searle AK, Sawyer MG, Baghurst PA, Hedley D. Resource factors for mental health resilience in early childhood: An analysis with multiple methodologies. Child Adolesc Psychiatry Ment Health [Internet]. 2013;7(1):6. Available from: http://capmh.biomedcentral.com/articles/10.1186/17532000-7-6

20. Shapiro SL. The integration of mindfulness and psychology. J Clin Psychol. 2009 Jun;65(6):555-60. Available from: https://onlinelibrary.wiley.com/doi/10.1002/jclp.20602

21. Shapiro SL, Carlson LE. The art and science of mindfulness: Integrating mindfulness into psychology and the helping professions. Washington: American Psychological Association; 2009. Available from: http://content.apa.org/books/11885-000

22. Keng S-L, Smoski MJ, Robins CJ. Effects of mindfulness on psychological health: A review of empirical studies. Clin Psychol Rev. 2011 Aug;31(6):104156. Available from: https://linkinghub.elsevier.com/retrieve/pii/S027273581100081X

23. Prazak M, Critelli J, Martin L, Miranda V, Purdum M, Powers C. Mindfulness and its Role in Physical and Psychological Health. Appl Psychol Heal WellBeing. 2012 Mar;4(1):91-105. Available from: https://onlinelibrary.wiley.com/doi/10.1111/j.1758-0854.2011.01063.x

24. Sala M, Rochefort C, Lui PP, Baldwin AS. Trait mindfulness and health behaviours: a meta-analysis. Health Psychol Rev. 2020 Jul 2;14(3):345-93. Available from: https://www.tandfonline.com/doi/full/10.1080/17437199.2019.1650290

25. Shorey RC, Brasfield H, Anderson S, Stuart GL. Differences in Trait Mindfulness Across Mental Health Symptoms Among Adults in Substance Use Treatment. Subst Use Misuse. 2014 Apr 16;49(5):595-600. Available from: http://www.tandfonline.com/doi/full/10.3109/10826084.2014.850310

26. Tan LBG, Martin G. Mind full or mindful: a report on mindfulness and psychological health in healthy adolescents. Int J Adolesc Youth. $2016 \mathrm{Jan}$ 2;21(1):64-74. Available from: http://www.tandfonline.com/doi/full/10.1080/02673843.2012.709174

27. Lu S, Huang C-C, Rios J. Mindfulness and academic performance: An example of migrant children in China. Child Youth Serv Rev. 2017 Nov;82:53-9. Available from: https://linkinghub.elsevier.com/retrieve/pii/S0190740917303730

Page $7 / 10$ 
28. Caballero C, Scherer E, West MR, Mrazek MD, Gabrieli CFO, Gabrieli JDE. Greater Mindfulness is Associated With Better Academic Achievement in Middle School. Mind, Brain, Educ. 2019 Aug;13(3):157-66. Available from: http://doi.wiley.com/10.1111/mbe.12200

29. Froeliger BE, Garland EL, Modlin LA, McClernon FJ. Neurocognitive correlates of the effects of yoga meditation practice on emotion and cognition: a pilot study. Front Integr Neurosci. 2012; 6. Available from: http://journal.frontiersin.org/article/10.3389/fnint.2012.00048/abstract

30. Salmon P, Lush E, Jablonski M, Sephton SE. Yoga and Mindfulness: Clinical Aspects of an Ancient Mind/Body Practice. Cogn Behav Pract. 2009 Feb; 16(1):59-72. Available from: https://linkinghub.elsevier.com/retrieve/pii/S1077722908001351

31. Gururaja D, Harano K, Toyotake I, Kobayashi H. Effect of yoga on mental health: Comparative study between young and senior subjects in Japan. Int J Yoga. 2011 Jan;4(1):7-12. Available from: http://www.ncbi.nlm.nih.gov/pubmed/21654969

32. Varambally S, Gangadhar BN. Current status of yoga in mental health services. Int Rev Psychiatry. 2016 May 3;28(3):233-5. Available from: https://www.tandfonline.com/doi/full/10.3109/09540261.2016.1159950

33. Danielly Y, Silverthorne C. Psychological Benefits of Yoga for Female Inmates. Int J Yoga Therap. 2017 Nov 1;27(1):9-14. Available from: https://meridian.allenpress.com/ijyt/article/27/1/9/137919/Psychological-Benefits-of-Yoga-for-Female-Inmates

34. Ramadoss R, Bose B. Transformative Life Skills: Pilot Study of a Yoga Model for Reduced Stress and Improving Self-Control in Vulnerable Youth. Int $J$ Yoga Therap. 2010 Jan 1;20(1):73-8. Available from: https://meridian.allenpress.com/ijyt/article/20/1/73/137768/Transformative-Life-Skills-PilotStudy-of-a-Yoga

35. Gaiswinkler L, Unterrainer $\mathrm{H}$. The relationship between yoga involvement, mindfulness and psychological well-being. Complement Ther Med. 2016 Jun;26:123-7. Available from: https://linkinghub.elsevier.com/retrieve/pii/S096522991630036X

36. Erkin Ö, Şenuzun Aykar F. The effect of the yoga course on mindfulness and self-compassion among nursing students. Perspect Psychiatr Care. 2021 Apr 28;57(2):875-82. Available from: https://onlinelibrary.wiley.com/doi/10.1111/ppc.12630

37. Brisbon NM, Lowery GA. Mindfulness and Levels of Stress: A Comparison of Beginner and Advanced Hatha Yoga Practitioners. J Relig Health. 2011 Dec 1;50(4):931-41. Available from: http://link.springer.com/10.1007/s10943-009-9305-3

38. Rashedi RN, Weakley M, Malhi A, Wajanakunakorn M, Sheldon J. Supporting positive behaviors through yoga: An exploratory study. J Posit Psychol. 2020 Jan 2;15(1):122-8. Available from: https://www.tandfonline.com/doi/full/10.1080/17439760.2019.1579364

39. Gulati K, Sharma SK, Telles S, Balkrishna A. Self-Esteem and Performance in Attentional Tasks in School Children after $4 \frac{1}{2}$ Months of Yoga. Int J Yoga. 2019;12(2):158-61. Available from: http://www.ncbi.nlm.nih.gov/pubmed/31143025

40. Hagen I, Nayar US. Yoga for Children and Young People's Mental Health and Well-Being: Research Review and Reflections on the Mental Health Potentials of Yoga. Front Psychiatry. 2014 Apr 2;5. Available from: http://journal.frontiersin.org/article/10.3389/fpsyt.2014.00035/abstract

41. Ganpat T, Sethi J, Nagendra H. Yoga improves attention and self-esteem in underprivileged girl student. J Educ Health Promot. 2013;2(1):55. Available from: http://www.jehp.net/text.asp?2013/2/1/55/119043

42. Noggle JJ, Steiner NJ, Minami T, Khalsa SBS. Benefits of Yoga for Psychosocial Well-Being in a US High School Curriculum. J Dev Behav Pediatr. 2012 Apr;33(3):193-201. Available from: https://journals.Iww.com/00004703-201204000-00001

43. Frank JL, Bose B, Schrobenhauser-Clonan A. Effectiveness of a School-Based Yoga Program on Adolescent Mental Health, Stress Coping Strategies, and Attitudes Toward Violence: Findings From a High-Risk Sample. J Appl Sch Psychol. 2014;30(1):29-49. Available from:

10.1080/15377903.2013.863259\%5Cnhttp://ezproxy.umsl.edu/login?url=http://search.ebscohost.com/login.aspx?

direct=true \&db=afh\&AN=94615095\&site=ehost-live\&scope=site

44. Steiner NJ, Sidhu TK, Pop PG, Frenette EC, Perrin EC. Yoga in an Urban School for Children with Emotional and Behavioral Disorders: A Feasibility Study. J Child Fam Stud. 2013 Aug 27;22(6):815-26. Available from: http://link.springer.com/10.1007/s10826-012-9636-7

45. Bhavanani AB, Udupa K, Madanmohan, Ravindra P. A comparative study of slow and fast suryanamaskar on physiological function. Int $\mathrm{J}$ Yoga. 2011 Jul;4(2):71-6. Available from: http://www.ncbi.nlm.nih.gov/pubmed/22022125

46. Mody BS. Acute effects of Surya Namaskar on the cardiovascular \&amp; metabolic system. J Bodyw Mov Ther. 2011 Jul;15(3):343-7. Available from: https://linkinghub.elsevier.com/retrieve/pii/S1360859210000562

47. Karthik PS, Chandrasekhar M, Ambareesha K, Nikhil C. Effect of pranayama and suryanamaskar on pulmonary functions in medical students. J Clin Diagn Res. 2014 Dec;8(12):BC04-6. Available from: http://www.ncbi.nlm.nih.gov/pubmed/25653936

48. Singh K, Bal BS, Vaz W. The Effect of Suryanamaskar Yogasana on Muscular Endurance and Flexibility Among Intercollege Yoginis. J Phys Educ Sport / Citius Altius Fortius. 2010 [cited 2021 May 12];27(2):61-7. Available from: http://search.ebscohost.com/login.aspx?

direct=true\&profile=ehost\&scope=site\&authtype=crawler\&jrnl=15828131\&AN=52365308\&h=HiPDouFFpoQ71Rv7A6GYcRk\%2FH26IN\%2F665Zbkk3sURWc

49. Godse AS, Shejwal BR, Godse AA. Effects of suryanamaskar on relaxation among college students with high stress in Pune, India. Int J Yoga. 2015 Jan;8(1):15-21. Available from: http://www.ncbi.nlm.nih.gov/pubmed/25558129

50. Phansikar M, Mullen SP. Cognitive and psychosocial effects of an acute sun salutation intervention among adults with stress. Preprint. 2021.

51. Goldberg DP. User's guide to the General Health Questionnaire. Windsor; 1988.

52. Mann RE, Paglia-Boak A, Adlaf EM, Beitchman J, Wolfe D, Wekerle C, et al. Estimating the Prevalence of Anxiety and Mood Disorders in an Adolescent General Population: An Evaluation of the GHQ12. Int J Ment Health Addict. 2011 Aug 27;9(4):410-20. Available from:

http://link.springer.com/10.1007/s11469-011-9334-5

53. Baksheev GN, Robinson J, Cosgrave EM, Baker K, Yung AR. Validity of the 12-item General Health Questionnaire (GHQ-12) in detecting depressive and anxiety disorders among high school students. Psychiatry Res. 2011 May;187(1-2):291-6. Available from:

https://linkinghub.elsevier.com/retrieve/pii/S0165178110006359

Page $8 / 10$ 
54. Brown KW, Ryan RM. The benefits of being present: Mindfulness and its role in psychological well-being. J Pers Soc Psychol. 2003;84(4):822-48. Available from: http://doi.apa.org/getdoi.cfm?doi=10.1037/0022-3514.84.4.822

55. Brown KW, West AM, Loverich TM, Biegel GM. Assessing Adolescent Mindfulness: Validation of an Adapted Mindful Attention Awareness Scale in Adolescent Normative and Psychiatric Populations. Psychol Assess. 2011 Dec [cited 2021 May 12];23(4):1023-33. Available from: /record/2011-03039001

56. Ghasemi A, Zahediasl S. Normality tests for statistical analysis: a guide for non-statisticians. Int J Endocrinol Metab. 2012;10(2):486-9. Available from: http://www.ncbi.nlm.nih.gov/pubmed/23843808

57. Mak C, Whittingham K, Cunnington R, Boyd RN. Efficacy of Mindfulness-Based Interventions for Attention and Executive Function in Children and Adolescents-a Systematic Review. Mindfulness (N Y). 2018 Feb 26;9(1):59-78. Available from: http://link.springer.com/10.1007/s12671-017-0770-6

58. Vhavle SP, Rao RM, Manjunath NK. Comparison of Yoga versus Physical Exercise on Executive Function, Attention, and Working Memory in Adolescent Schoolchildren: A Randomized Controlled Trial. Int J Yoga. 2019;12(2):172-3. Available from: http://www.ncbi.nlm.nih.gov/pubmed/31143027

59. Desai R, Tailor A, Bhatt T. Effects of yoga on brain waves and structural activation: A review. Complement Ther Clin Pract. 2015 May;21(2):112-8. Available from: https://linkinghub.elsevier.com/retrieve/pii/S1744388115000110

60. Hernández SE, Suero J, Barros A, González-Mora JL, Rubia K. Increased Grey Matter Associated with Long-Term Sahaja Yoga Meditation: A Voxel-Based Morphometry Study. Ben Hamed S, editor. PLoS One. 2016 Mar 3;11(3):e0150757. Available from: https://dx.plos.org/10.1371/journal.pone.0150757

61. Eslinger PJ, Flaherty-Craig C V., Benton AL. Developmental outcomes after early prefrontal cortex damage. Brain Cogn. 2004 Jun;55(1):84-103.

62. Alexander MP, Benson DF, Stuss DT. Frontal lobes and language. Brain Lang. 1989 Nov;37(4):656-91.

63. Frank JL, Bose B, Schrobenhauser-Clonan A. Effectiveness of a School-Based Yoga Program on Adolescent Mental Health, Stress Coping Strategies, and Attitudes Toward Violence: Findings From a High-Risk Sample. J Appl Sch Psychol. 2014 Jan 2; 30(1):29-49. Available from: http://www.tandfonline.com/doi/abs/10.1080/15377903.2013.863259

64. Hagen I, Nayar US. Yoga for children and young people's mental health and well-being: Research review and reflections on the mental health potentials of yoga. Front Psychiatry. 2014; 5(APR).

65. Brown KW, Ryan RM. The benefits of being present: Mindfulness and its role in psychological well-being. J Pers Soc Psychol. 2003;84(4):822-48. Available from:http://doi.apa.org/getdoi.cfm?doi=10.1037/0022-3514.84.4.822

\section{Figures}

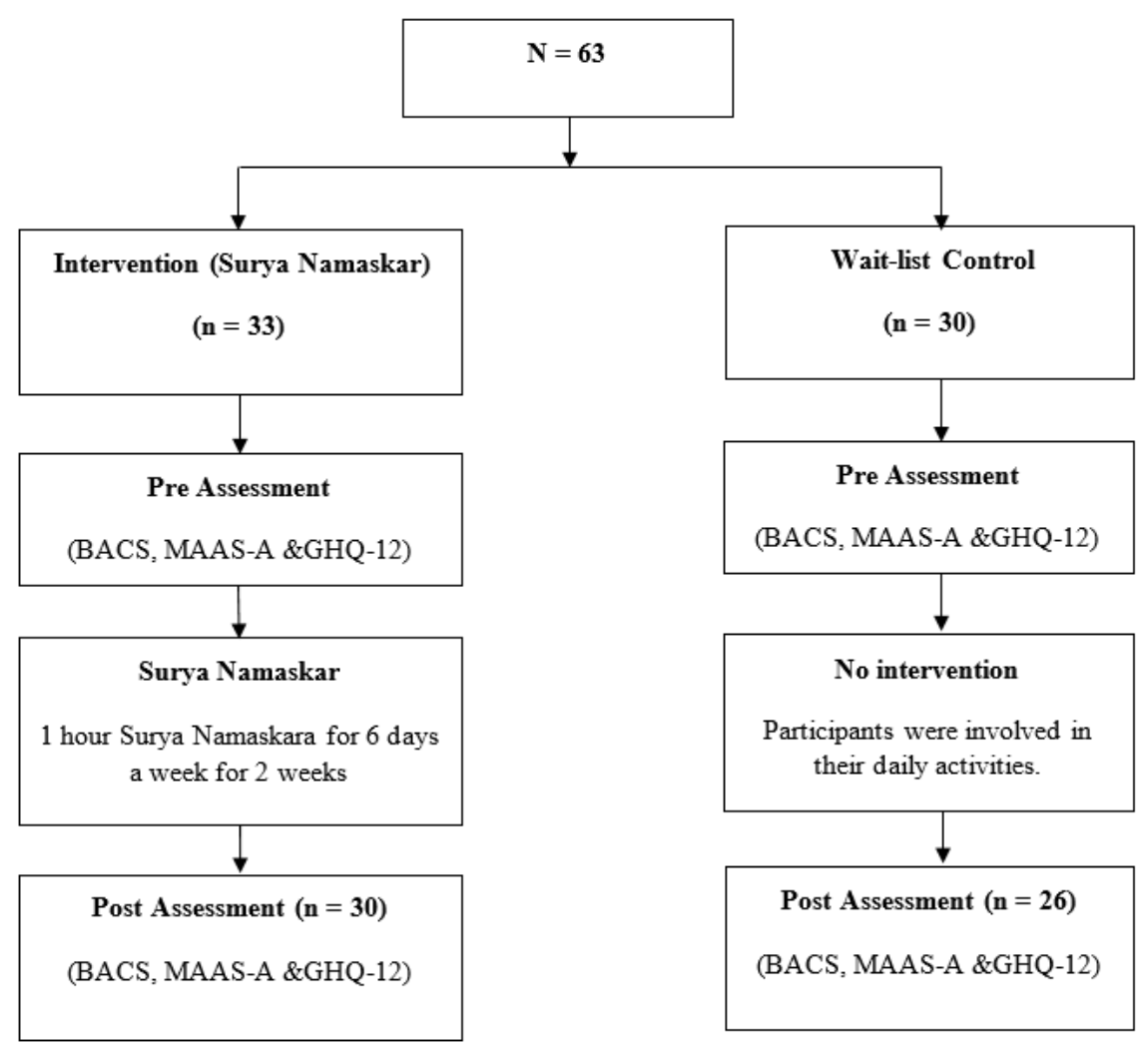

Figure 1

Trial Profile 


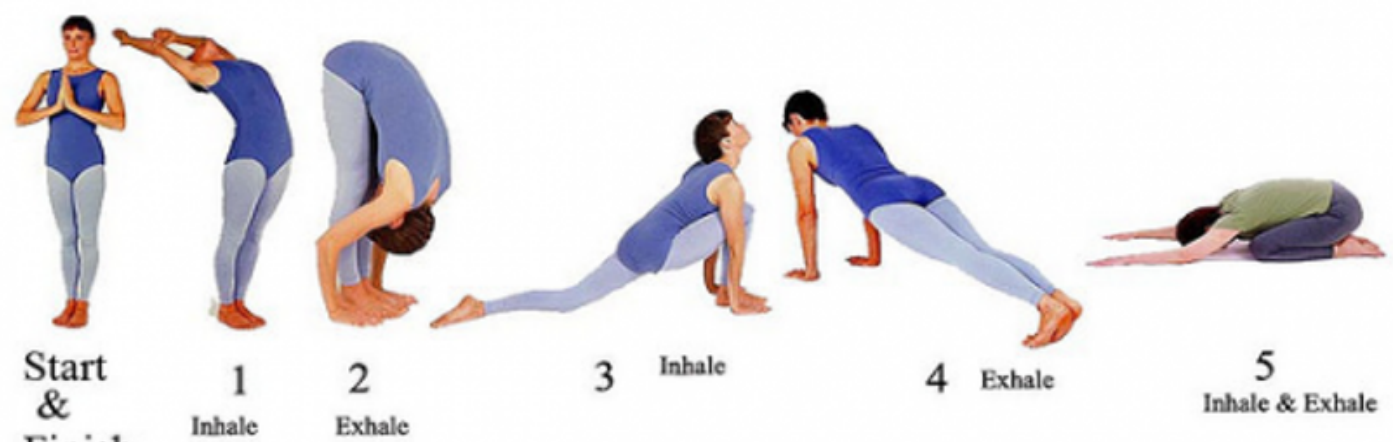

Finish

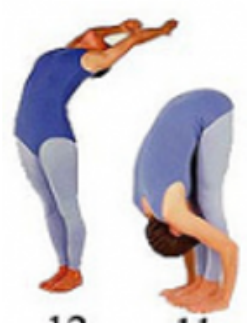

12

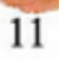

Inhale Exhale

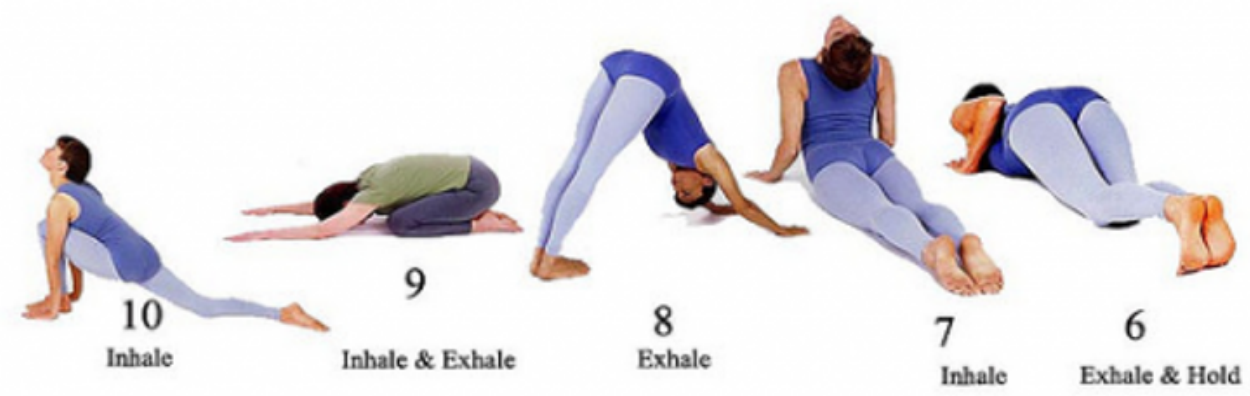

Figure 2

12 Steps Surya Namaskar Source: Dr. Viral Thakkar (2017), Surya Namskar- The 12 Commandments of sun!. Retrieved from: https://goqii.com/blog/suryanamaskar-the-12-commandments-of-sun/ 